\title{
TIME PARAMETERS OF NONVERBAL COMMUNICATION AND PERSONAL COMMUNICATIVE COMPETENCE
}

\author{
Alla K. Bolotova \\ National Research University Higher School of Economics \\ Moscow, Russia
}

Cognitive behavior in interpersonal relations is always connected with time characteristics such as sequence, rhythm, and succession of actions. In our research we attempted to determine the role of time parameters in the development of the following social communications: (a) interpersonal relations, (b) communicative acts, and (c) the process of structuring social behavior. We intended to show the role of time in acquiring and mastering social contacts. In our research we outlined a number of methods for developing time competence and various conscious and unconscious ways to organize time and to create an atmosphere of understanding, acceptance, and trust in interpersonal nonverbal communication. The time characteristics of social behavior and its nonverbal manifestation can exert a positive influence on communicative activity and can determine time competence in communication. Ignoring time parameters in the self-realization and self-actualization of personality introduces a certain destructive element into the process of interpersonal relations; hence the necessity of teaching competence in communication arises. Teaching is carried out in the process of training and includes several stages: the introductory stage and the stages of intensification, integration, avoidance, and others. Thus, time management and the process of teaching time management allow one to discover time resources for the self-organization of one's personality over a lifetime.

Keywords: communicative competence, time, interpersonal relations, nonverbal communication.

Nonverbal behavior and its study appear to be not only an integral aspect of interpersonal communication but also a reality in modern social psychology, providing an independent influence on the results of the communicative process. Although spatiotemporal parameters of nonverbal acts always precede interpersonal communication, this aspect 
of the rational organization of interpersonal and communicative competence is still underdeveloped.

Temporal characteristics of nonverbal behavior are reflected in a certain temporal order in the structure of nonverbal acts, as is indicated in the well-established tradition of studies on nonverbal communication in European social psychology. The contributions of such researchers of nonverbal behavior as Argyle (1985), Goutts (1977) and Sheflen (1984) are worth considering. Thus, as Argyle points out, eye-to-eye contact ("mutual glance") that takes too long ("piercing eye") may be perceived as overly intrusive. Such contact dramatically narrows psychological distance and is perceived negatively by the partner, and so it destroys the act of communication and breaks mutual understanding. At the same time Kleck (1988) has found that people with open, friendly faces are perceived as being attractive and capable of inducing confidence and sympathy. Avoidance of eye-to-eye contact in nonverbal behavior may be perceived as a signal of uncertainty, anxiety, and lack of confidence (Sheflen, 1984). Other researchers state that there is a positive correlation between nonverbal behavior and the positive communication of confidence, which is denoted by a certain "rapport."

In general, all foreign studies on nonverbal behavior investigate not only individual characteristics of nonverbal behavior or not simply partial acts of behavior but also variables that combine the individual manifestations of nonverbal reactions of both participants in a communication. These variables are eye contact, congruence, mirror poses, and rapport, or timing movements. The concept of congruent poses appears in Scheflen (1984). The adoption of similar poses in communication within a dyad indicates similarity of views and confidence in relationships. Incongruent poses indicate the demonstrative manifestation of differences in attitudes and status. In Bernieri F.\& Rosental R. (1991) mirror-congruent poses in therapist-client relationships are referred to as indicators of far greater understanding than are incongruent poses. Similar data on relationships between interviewers and respondents are found in Dabbs (1979). Thus, there is much evidence that mirror position and rapport have an influence on the adoption of congruent posture by the partner, which leads to consistency in the expectations of positive results in communication.

In their studies Bernieri and Rosental (1991) highlight the importance of "interpersonal coordination," which includes rhythm, simulta- 
neous movements, and smooth meshing interaction. According to the authors, the coordination of behavior, which can be observed, is divided into two main types of nonverbal actions in interpersonal communication: similar behavior and temporal synchrony. In its turn, interpersonal temporal synchrony includes such components as rhythm, simultaneity, and sequencing. All these components of nonverbal behavior are investigated as determinants of the development of nonverbal communication. However, study of the components of interpersonal coordination in light of their temporal coordination appears to be crucial. In our opinion, these components constitute the specific temporal structure of nonverbal interaction. However, in peer-reviewed foreign literature we have found no studies on the structure of the temporal organization of nonverbal interaction.

In Russian psychology the study of nonverbal behavior consists essentially of the theoretical and empirical study of nonverbal communication (Gorelov, 1980; Kovalev, 1987; Labunskaya, 1986), the interpretation and understanding of nonverbal behavior, reflections on nonverbal behavior, the search for special characteristics of expressive behavior through interpretations of nonverbal reactions, and so forth. To summarize the studies described, we assume that nonverbal behavior is determined by communication, but this assumption does not preclude the special significance of nonverbal behavior. Such behavior is included in the communication process as its own product, on the one hand, and as a reality, on the other hand, and exerts an independent influence on the results of interpersonal interactions (Rubinschteyn, 1997). In the process, the space-time imperative acts as a rather important but poorly investigated aspect of the organization of nonverbal behavior .

Considering the relationship between nonverbal behavior and communicative competence, we believe that this relationship necessarily includes the temporal organization of the structure of the nonverbal acts. Our assumption is based particularly on the study described by Bodalev (1983), who showed that internal processes are dynamically expressed in the appearance and behavior of a person as a set of acts and activities organized in the space-time structure; these activities precede the content of the communicative process.

The temporal organization of the structure of the nonverbal form of interaction includes the frequency, duration, and sequence of the additional involvement of the various elements of kinesics in nonverbal 
communication. Among them are the eyes and mutual glances, gestures, facial expressions, congruent and mirror poses, rapport, and also their mutual synchronicity, cooperation, or interpersonal coordination of nonverbal acts. The kinesics of nonverbal communication are a kind of space-time organizer of interpersonal communication and thereby create an interpersonal form of space-time. In the context of the spatiotemporal regulation of interpersonal interaction, it is important to note that each partner should be provided with opportunities for solving problems and with time to solve them, to make selective decisions, to reflect, and to make a final decision. Thus, in the field of joint communications, the interaction process occurring in the space and time of actual psychological interactions appears to be relevant in the "here and now" (Rogers, 1965). The openness of interacting agents in a single space-time and elements that are built spontaneously on this basis-equality, mutual understanding, and trust-are the fundamental factors for ensuring effective and efficient communication when "mutual emotional satisfaction" and the emergence of empathic experiences occurs. As Abulhanova-Slavskaja (1991) states, it is appropriate to consider a communicative situation as a "temporary space," where the emotional, verbal, and behavioral manifestations of mutual personal contact are combined. In fact, the concept of a communicative situation involves an implicit understanding of a certain time formation, space-time, in which, to use Rubinschteyn's term (1997), some "balance of power" exists for some period of time and then disappears, whether resolved or not. Productive resolution of this situation depends not only on the accuracy of contact - that is, "the hit of the semantic field of the subject into the semantic field of the object" - but also on the time parameter of this hit, which is determined by the readiness of the interacting agents to "spend" their own time on empathy and effective assistance to achieve the psychological well-being of the partner (Kovalev, 1987; Bolotova, 2007; Petrovskaya, 1989).

While Russian psychology exploits the concept of contact to assess relationships of understanding and acceptance in the communicative act, foreign psychology considers the concept of "rapport" to be quite common and relevant to these relationships. The time the partners spend getting into the interaction appears to be the common ground uniting these concepts. The rhythm of the interaction is the emergence of nonverbal acts associated with certain elements of their temporal frequency. Simultaneous synchronous actions include muscle movements, gestures, 
vocalizations, facial expressions, and mirror poses, as well as body poses and even mental states. Smooth meshing interaction is the coherence between the partners and their ability to relax during the whole time of the communication. The concepts of contact, rapport, and interpersonal coordination emphasize the function of the nonverbal variables uniting the partners. In our opinion, it is crucial to study the components of interpersonal coordination in their time interdependence. In our view, these components constitute the specific temporal structure of nonverbal interaction.

Our research review of the problem of nonverbal communication indicates that such individual timing parameters of nonverbal interaction as eye contact, mutual glances, mirror posture, poses, and their impact on the partner's positive assessment of the situation and the development of productive communication are fully presented in various studies. However, in the studies we have found no evidence of nonverbal communication as a manifestation of dialogical communication, preceding or accompanying either the success and productivity or the destruction of the process of communication. We have not seen any research on temporal organization of the structure of nonverbal interaction and its correlation with the indicators of dialogical communication and with the efficiency of communication either. The temporal organization of the structure of nonverbal interaction in the form of interpersonal communication consists of the frequency, duration, and sequence of the presentation of nonverbal acts accompanying the communication process. The basic premise we have as a basis for studying the temporal organization of the structure of nonverbal interactions is the simultaneous manifestation of similar kinesics by both partners in the communicative act. With this criterion, we have highlighted the specific components of the structure of nonverbal interactions that link both sides of the interaction together. These are eye contact, mirror poses, gestures, and facial expressions. It is particularly important to determine the role of sequence, or the simultaneous inclusion of these components in the process of communication. No such integrated studies are available in the psychological literature.

We assume that some elements of the temporal structure of nonverbal interactions take precedence over others in understanding and accepting a partner in the creation of dialogical communication. Probably, this priority changes depending on the conditions and objectives of the interaction. 
Thus, in some of our experiments, where the subjects acted as interviewees and assistants, temporal instances of the simultaneous coincidence of facial expressions, postures, and gestures (their frequency and duration) have been recorded with the following results. The complete absence of facial expressions, mirror matches, gestures, and postures in the time structure of nonverbal interactions reduces dialogical communication and does not promote an atmosphere of trust and the creation of a partnership. At the same time, the presence of these elements, at least at the beginning of the communicative process, raises the level of trust and the possibility of creating a partnership. As for the lack of eye contact (mutual glances) in the interview process, it proved to be the most inefficient way to create a partnership and a dialogue. Statistically significant differences have not been found (Bolotova, 2006; Makarevskaya, 1995).

Our studies have confirmed the assumption that the saturation of the temporal structure of nonverbal interaction with mirror facial expressions and poses and eye-to-eye contact promotes dialogical communication. At the same time the presence of only mirror poses and gestures during the time of communication and a complete lack of eye contact reduces the possibility of dialogical communication. There is a special correlation between the duration of the mirror positions and the duration of eye contact. The duration and the number of mirror poses and gestures early in the communication process contribute to mutual glances, but their continuous presence reduces dialogical communication. The temporal structure of these acts of nonverbal communication should be of a discrete character. The duration and the number of matches of glances (which are called "eye to eye") can affect the development of favorable contacts in the beginning of communication, while constant, piercing gazing at the partner destroys the possibility of contact. (Here we are talking about a "serious, boring look.") However, the complete absence of a mutual exchange of glances for the duration of the communication is not conducive to favorable contact with a partner. Consequently, an important quality, a kind of ethical and psychological tact, is the ability to avoid obsessive gazing at a long-term partner. These skills are one side of the communicative competence of an individual. It is important to bear in mind that the length of the mirror posture and the duration of eye contact are inversely related. An increase in the duration of mirror poses must be accompanied by a decrease in the duration of both mutual glances and mirror facial expressions. Otherwise, the effectiveness 
of dialogical communication is reduced. The validity of our assumptions is confirmed by the experimental data, some of which are presented in the conclusion of this article.

\section{Hypothesis}

The development of communicative acts and the process of structuring social behavior are related to the time characteristics of verbal and nonverbal behavior. Dyad communication possesses a time structure different from the time structure in group communication. In group communication the verbal components are usually superimposed-that is, some appear later, after the previously formed nonverbal interaction. Psychological moods of partners and their social roles are represented first in kinesics and only afterwards in words.

The time structure of the nonverbal interaction of partners in dyad communication includes simultaneous or successive manifestations of such kinesics as congruent poses, facial expressions, and eye-to-eye contact.

The effectiveness of the dialogue and an atmosphere of acceptance and trust are provided by the duration, succession, and frequency of the rotation of these acts in a certain period of time. Cognitive behavior and conscious regulation of the time parameters of nonverbal communication lead to personal self-realization and communicative competence.

\section{Method}

The research was based on the works of Goutts (1977), Bernieri \& Rosental (1991), and Sheflen (1984), who studied the phenomena of interaction: the mirror congruence of poses, the frequency and duration of eye-to-eye contact, and facial expressions. The succession, simultaneity (synchrony), and duration of these components of nonverbalization in the structure of a dialogue were registered by video-recording micromovements and chronometry.

One hundred thirty students (two groups of 65 people each) took part in the experiment. Three conditions were defined for conducting a dialogue: (1) congruent poses and facial expressions; (2) congruent poses and eye-to-eye contact; (3) eye-to-eye contact, facial expressions, and congruent poses. The Wilcoxon criterion was used to find significant differences in dialogue evaluation. 


\section{Results}

As shown in Table 1 , the time saturation of a dialogue ( $t=10 \mathrm{~min}$ ) with nonverbal components such as facial expressions, congruent poses, and eye-to-eye contact (3) significantly increases trust and understanding in communication. At the same time, congruent poses and facial expressions without eye-to-eye contact (1) decrease understanding, trust, and acceptance in communication.

Table 1

Evaluation of Dialogue Performance According to the Duration of Communication $(t)$ and the Number of Nonverbal Components (Wilcoxon Criterion) (Group I Results)

\begin{tabular}{|c|c|c|c|}
\hline & \multicolumn{3}{|c|}{ Nonverbal component } \\
\hline $\begin{array}{c}\text { Duration } \\
\text { of communication } \\
(t=10 \text { min })\end{array}$ & $\begin{array}{c}\text { Congruent } \\
\text { poses + facial } \\
\text { expressions (1) }\end{array}$ & $\begin{array}{c}\text { Congruent poses } \\
\text { +eye-to-eye } \\
\text { contact }(2)\end{array}$ & $\begin{array}{c}\text { Congruent poses + } \\
\text { facial expressions + } \\
\text { eye-to-eye contact (3) }\end{array}$ \\
\hline $\begin{array}{c}\text { 1. Beginning of the } \\
\text { dialogue }(t=3 \text { min })\end{array}$ & $487.5^{*}$ & 517 & 584.5 \\
\hline $\begin{array}{c}\text { 2. Middle of the dialo- } \\
\text { gue }(t=5 \text { min })\end{array}$ & $487.5^{*}$ & 510 & $620^{*}$ \\
\hline $\begin{array}{c}\text { 3. Total dialogue } \\
(t=10 \text { min })\end{array}$ & $556^{*}$ & 590 & $680^{* *}$ \\
\hline
\end{tabular}

${ }^{\star} p<0.05 .{ }^{* *} p<0.01$.

Table 2

Evaluation of Dialogue Performance According to the Duration of Communication $(t)$ and the Minimization of the Nonverbal Components (Wilcoxon Criterion) (Group II Results)

\begin{tabular}{|c|c|c|c|}
\hline & \multicolumn{3}{|c|}{ Nonverbal component } \\
\hline $\begin{array}{c}\text { Duration of commu- } \\
\text { nication }(t=10 \mathrm{~min})\end{array}$ & $\begin{array}{c}\text { Congruent } \\
\text { poses (a) }\end{array}$ & $\begin{array}{c}\text { Facial expres- } \\
\text { sions (b) }\end{array}$ & $\begin{array}{c}\text { Eye-to-eye } \\
\text { contact (c) }\end{array}$ \\
\hline $\begin{array}{c}\text { 1. Beginning of the } \\
\text { dialogue }(t=3 \mathrm{~min})\end{array}$ & 215.5 & 154 & 250.5 \\
\hline $\begin{array}{c}\text { 2. Middle of the dialo- } \\
\text { gue }(t=5 \text { min) }\end{array}$ & 246 & $198^{*}$ & 328 \\
\hline $\begin{array}{c}\text { 3. Total dialogue } \\
(t=10 \mathrm{~min})\end{array}$ & $268.5^{*}$ & 211 & $364.5^{* *}$ \\
\hline
\end{tabular}

${ }^{\star} p<0.05 .{ }^{* *} p<0.01$. 
The presence of only one nonverbal component during the entire act of communication has a negative influence on the index of understanding and acceptance in the dialogue, as the experimental data of Group II show (Table 2).

A comparison of Group I and Group II results shows that the most important role in dyad communication is played by such nonverbal components as eye-to-eye contact, and these data are supported by the research of Argyle (1985), Dabbs (1979), and La France (1989). However, a significant increase in the number and duration of eye-to-eye contacts in a dialogue performance turn out to be disadvantageous and reduce trust and acceptance in communicative acts. The aggregate frequency of eye-to-eye contact (as shown in the statistical processing of our data) should not exceed five to eight coincidences per minute, each coincidence lasting no longer than 5 seconds. The duration of a congruent pose can take up to $80 \%$ of the total time of the dialogue in synchronous coincidences.

Dialogue performance, according to our research, can be improved by increasing the duration of a congruent pose and simultaneously decreasing the number and duration of eye-to-eye contacts. Our inference is supported by correlation data (Table 3).

Table 3

Correlation of the Structural Components of Nonverbal Interactions

\begin{tabular}{|c|c|c|c|}
\hline \multicolumn{2}{|c|}{ Number of nonverbal components } & \multicolumn{2}{c|}{ Duration of nonverbal components } \\
\hline Eye-to-eye contact & Congruent poses & Eye-to-eye contact & Congruent poses \\
\hline-.10 & -.18 & -.09 & $-.25^{*}$ \\
\hline
\end{tabular}

Note. $N=65 .{ }^{*} p<0.01$.

Trust and acceptance occur on account of the cognitive behavior of the partners in interpersonal communication when the time factor is considered in the structuring of social behavior. The time factor determines personal communicative competence and self-realization.

\section{Discussion}

We regard time synchronism of the interaction of the partners in a communicative act as an index of trust, acceptance, and mutual under- 
standing. Synchronism of congruent poses shows similarity in opinions and social roles.

A congruent pose in communication is viewed as an index of understanding and intimacy, and the aggregate duration of congruent poses during the whole dialogue has special significance. Along with research on the frequency and duration of the nonverbal component in communication, we consider it most important to study the influence of time sequence and the order in which these components are included in the cognitive structure of the dialogue. Our experiments showed a positive correlation between acceptance of the partner and both the duration of a congruent pose and the structured frequency of eye-to-eye contact. However, excessive duration and intensity of eye-to-eye contact per time unit can worsen dialogue performance and introduce monotony into an act of communication. Mastering the time structure of nonverbal communication requires specific training and is a part of personal communicative competence; it also contributes to self-realization over a lifetime.

\section{Conclusions}

Cognitive behavior in interpersonal relations is connected with the conscious regulation of time parameters and the structure of the nonverbal component in communication. The level of dialogue performance and acceptance in communication between two partners is connected with equal frequency, duration, and synchronism of nonverbal components per time unit.

Personal communicative competence includes time organization of the structure of nonverbal interaction and the ability to introduce kinesics into the dialogue in a consecutive and synchronous way.

Congruent poses are one of the most significant components of an interaction, provided that eye-to-eye contact and facial expressions are sequentially included in a communicative act during the whole period of the dialogue.

Duration of a congruent pose and the number and duration of eyeto-eye contacts are in inverse relation. An increase in the duration of a congruent pose must be accompanied by a concurrent decrease in eyeto-eye contact.

The communicative competence of an individual includes, in addition to specific skills and knowledge, the temporal characteristics of 
nonverbal interactions. Such characteristics may contribute to the development of skills in the temporal structuring of the conscious regulation of interpersonal interactions. Communication skills, in this case, suggest the adequacy, timeliness, and consistency of the inclusion of the nonverbal components of kinesics and expression into the process of interpersonal communication. The development of these abilities and skills and their use in the interactional or conversational process contribute to the effectiveness of communicative interaction in the dialogue.

Understanding and acceptance of the partner, which indicate the level of communicative competence, lead to coordination of positions and defuse tensions and barriers to communication in the temporary space of various social situations.

\section{References}

Abulhanova-Slavskaja, K.A. (1991). Strategija czizny [Strategy of life]. Moscow: Misl. Argyle, M. (1985). Eye-contact, distance and affilitation. Gambridge Universiti Press.

Bernieri, F., \& Rosental, R. (1991). Interpersonal Coordination: Fundamentals of Nonverbal Behavior (pp. 401-432). Gambridge Universiti Press.

Bodalev, A.A. (1983). Lichnost $i$ obschenie [Personality and communication]. Voronezh: International Pedagogic Academy.

Bolotova, A.K. (2006). Psychologiya organizaciy vremeny [Psychology of time organization]. Moscow: Aspect Press.

Bolotova, A.K. (2007). Chelovek i vremya v poznanii, deatelnosti, obwenii [A man and time in cognition, activity and communication]. Moscow: State University - Higher School of Economics Publishing House.

Dabbs, J. (1979). Similarityand interpersonalinfluence. $77^{\text {th }}$ Annual Convention of the American Psychological Assotiation, 4, 337-338 (Summary).

Gorelov, I.N. (1980). Neverbalnuye componenty communicatiy [Nonverbal components of communications]. Moscow: Science.

Goutts, L. (1977). Nonverbal compensatory reactions in interpersonal proximity. Journal of Social Psychology, 102 (2), 283-290.

Kleck, R. (1988). Case and eye-contact: a research review. Psychology Bulletin, 100 (1), 78-100.

Kovalev, G.A. (1987). O sisteme psychologicheskogo vozdeystviya. [About the system of social influence]. Moscow.

Labunskaya, V.A. (1986). Neverbalnoye povedeniye [Nonverbal behavior]. Rostovon-Don: Rostov University Publishing House. 
La France, M. (1989). Nonverbal syncdhrony and Rapport. Journal of Nonverbal Behavior, 5, 139-154.

Makarevskaya, A.V. (1995). Vremennaya organizaciya neverbalnogo vzaimodeystviya [Time organization of nonverbal interactions]. Moscow.

Petrovskaya, L.A. (1989). Kompetentnosty v obscheniy [Competence in communication]. Moscow: Moscow State University.

Rogers, C. (1965). Client-centered Therapy. Boston: Houghton Mifflin.

Rubinschteyn, S.L. (1997). Chelovek i mir [A man and the world]. Moscow: Piter.

Sheflen, A. (1984). The significance of posture in communication systems. Psychiatry, 27, 316-331. 